\title{
O ensino médio e as habilidades sociais: um estudo com a escala Messy
}

\author{
Rogério Gomes Neto \\ Instituto de Terapia e Estudo do Comportamento Humano, Campinas - SP - Brasil \\ Roberta Gurgel Azzi' \\ Ana Paula Basqueira \\ Universidade Estadual de Campinas, Campinas - SP - Brasil \\ Daniela Couto Guerreiro-Casanova \\ Universidade Nove de Julho, São Paulo - SP - Brasil
}

\begin{abstract}
Resumo: O presente estudo teve como objetivo ampliar o conhecimento sobre as relações sociais no ensino médio por meio da identificação, descrição e análise das habilidades sociais dos jovens alunos. Participaram do estudo 219 alunos do ensino médio. A coleta foi realizada por meio do questionário de caracterização do participante e da escala Messy de habilidades sociais. Os resultados mostraram diferenças significativas no fator habilidades sociais/assertividade, com escores maiores na faixa etária 16-17 anos e no gênero feminino. No fator agressividade/comportamento antissocial, constataram-se diferenças significativas, com maior escore no período noturno de aula e maior escore para os alunos da $2^{\mathrm{a}}$ série do ensino médio. Os resultados também indicaram valores altos para toda amostra quanto ao fator habilidades sociais/assertividade e valores baixos quanto ao fator agressividade/comportamento antissocial. Os resultados, em parte, se alinham com a literatura e alertam para o equívoco de generalizar a relação entre comportamentos agressivos e escolas de ensino médio.
\end{abstract}

Palavras-chave: ensino médio; habilidades sociais; estudantes; relações sociais; educação.

\section{HIGH SCHOOL AND SOCIAL SKILLS: A STUDY WITH MESSY SCALE}

Abstract: This study aimed to increase knowledge about social relationships in high school through the identification, description and analysis of social skills of young students. The study included 219 middle school students. Data were collected through questionnaire for participant characterization and the social skills Messy scale. The results showed significant differences in the factor social skills/assertiveness, with higher scores in the age group of 16-17 years and in females. In the aggressiveness/antisocial behavior factor, significant differences were found, with higher scores for the night class period and for students in 2 nd year of high school. The results also indicated high values for the whole sample regarding social/assertiveness skills factor and low values for aggressiveness/antisocial behavior factor. The results, in part, align with the literature and point to the mistake of generalizing the relationship between aggressive behavior and high schools.

Keywords: high school; social skills; students; social relations; education.

${ }^{1}$ Endereço para correspondência: Roberta Gurgel Azzi, Universidade Estadual de Campinas, Avenida Bertrand Russell, 801, Cidade Universitária "Zeferino Vaz" - Campinas - SP - Brasil. CEP: 13083-865. E-mail: azzi@unicamp.br. 


\begin{abstract}
Resumen: El presente estudio tiene como objetivo la profundización de las relaciones sociales en la escuela secundaria mediante la identificación, descripción y análisis de las habilidades sociales de los estudiantes. Participaron en el estudio 219 estudiantes de secundaria. Se utilizaron dos instrumentos: cuestionario de caracterización de participantes y la escala de habilidades sociales (Messy). Los resultados mostraron diferencias significativas en el factor habilidades sociales/asertividad con puntuaciones mayores en las edades de 16-17 años y género femenino. En el factor agresividad/comportamiento antisocial se constataran diferencias significativas con mayor puntuación en estudiantes del período nocturno de clases y mayor puntuación para los alumnos del $2^{\circ}$ año de la enseñanza secundaria. Los resultados también indicaron valores altos para toda la muestra cuanto al factor habilidades sociales/ asertividad y valores bajos para el factor agresividad/comportamiento antisocial. Los resultados en parte se alinean con la literatura y alertan para el equívoco de generalizar la relación entre comportamientos agresivos y escuelas de enseñanza secundaria.
\end{abstract}

Palabras clave: escuela secundaria; habilidades sociales; estudiantes; relaciones sociales; educación.

Com duração mínima de três anos, o ensino médio tem por objetivo consolidar e aprofundar o aprendizado do ensino fundamental, além de preparar o estudante para trabalhar e exercer a cidadania (Brasil, 2010). Tem como propósito ensinar teoria e prática em cada disciplina, buscando facilitar a compreensão das profissões, além de viabilizar o desenvolvimento do pensamento crítico e da autonomia intelectual do aluno.

Importantes estudos foram desenvolvidos sobre o ensino médio no Brasil, como o de Abramovay e Castro (2003) que focou principalmente no que os alunos percebiam e o que esperavam desse nível de ensino. Os autores encontraram quatro principais tendências apontadas pelos alunos como as finalidades do ensino médio: preparação para o vestibular, busca de um futuro melhor, preparação para o mercado de trabalho e educação para a cidadania.

Teixeira (2011) aponta que há um desinteresse mundial dos jovens pela escola e destaca a urgência na necessidade de investimentos na descoberta e no aperfeiçoamento de novas metodologias e processos educacionais. Nessa perspectiva, é provável que a prevalência de modelos tradicionais e arcaicos colabore para o desinteresse do jovem pela escola. $O$ desafio proposto pela autora é grande, pois traz à tona a necessidade de contemplar, no processo educacional da juventude, a enorme quantidade de informações e conhecimentos produzidos ininterruptamente em todas as áreas do conhecimento, de modo a possibilitar a integração e a articulação entre elas. $O$ crescimento do conhecimento e do interesse pela área de tecnologia de informação entre os jovens ilustra essa demanda.

O reconhecimento de que a juventude demanda novas propostas das escolas e que está cada vez mais conectada a um mundo de informações por meio das tecnologias nos remete a compreender também a escola como reflexo dessa "nova" juventude, cada vez mais permeada pela diversidade de comportamentos, atitudes, hábitos, costumes e valores. A partir dessa heterogeneidade, configuram-se problemas e imagens que alunos, professores e membros do corpo técnico-pedagógico constroem sobre si e 
sobre os outros integrantes da comunidade escolar. Para isso, colaboram as experiências externas e internas ao ambiente escolar. É relevante avaliar as experiências internas quando se observa a dimensão e a extensão da vida acadêmica na vida da maioria das pessoas (Dayrell, 2007).

De acordo com Dayrell (2007), a escola, no ensino médio, constitui-se como um importante agente de socialização, embora não o único. Para o autor, no caso específico das classes sociais mais baixas, a escola tem um papel socializador mais específico ainda, visto que muitas vezes encontra-se em regiões periféricas das cidades e se constitui como uma das poucas edificações que abrigam possibilidades de os jovens se encontrarem, já que essas regiões geralmente são privadas de boas condições de urbanismo, como praças públicas, centros comunitários e praças de esportes.

Teixeira (2011) aponta que as experiências sociais com a juventude em ações dentro e fora da instituição escolar têm se mostrado muito úteis ao desenvolvimento dos jovens. $O$ incentivo às práticas que produzam e incentivem interações entre eles por meio do desenvolvimento de expressões artísticas e culturais, do estímulo ao retorno e à frequência assídua à escola (e a possibilidade de, por esse meio, aproximar-se do mercado de trabalho), da participação em programas de economia solidária e cooperativismo tem se mostrado um forte aliado na luta contra a criminalidade entre os jovens (especialmente contra o tráfico de drogas, muito atrativo economicamente), sinalizando um alento à sobrevivência física da juventude tão exposta às mazelas sociais. Conhecer mais sobre as relações sociais que os jovens estabelecem, mais especificamente sobre suas habilidades sociais, pode favorecer não somente o desenvolvimento de estratégias para uma aproximação entre juventude e escola, mas também a compreensão sobre o universo juvenil como um todo.

De acordo com Gresham (2009), as crianças e os adolescentes precisam adquirir habilidades sociais para desenvolver relacionamentos bem-sucedidos com colegas, pais e professores. As habilidades sociais são competências que facilitam a iniciação e manutenção de relacionamentos sociais positivos, favorecem a aceitação por colegas e também produzem ajustamento escolar satisfatório. Nesse sentido, habilidades sociais podem ser definidas como comportamentos aprendidos e socialmente aceitáveis que permitem ao indivíduo interagir efetivamente com outros e esquivar-se de comportamentos não aceitáveis que resultem em interações sociais negativas.

As tarefas sociais compõem, certamente, parte fundamental do desenvolvimento humano. No entanto, embora as relações sociais sejam parte do cotidiano das pessoas, a socialização não é autônoma ou reflexa. De acordo com Del Prette e Del Prette (1999), os seres humanos nascem com um equipamento biológico cuja capacidade para se desenvolver no âmbito das interações sociais depende de vários fatores, como os cuidados com saúde e higiene, e estimulação adequada. É importante considerar que o desenvolvimento das habilidades sociais é bastante complexo e dependente de inúmeras variáveis e da inter-relação entre estas. Bolsoni-Silva (2002) aponta que as dimensões pessoais, situacionais e culturais do comportamento são fundamentais para 
o desempenho social e consequente desenvolvimento das habilidades sociais. Nesse sentido, a autora aponta que as características do indivíduo, as condições específicas de cada situação e as características histórico-culturais do ambiente são fundamentais para o desenvolvimento das habilidades sociais, dado que essas três dimensões consideradas simultaneamente determinam a construção dos repertórios comportamentais de modo geral. Essa proposição se alinha com o pressuposto da análise do comportamento (Skinner, 1984) de que qualquer comportamento é produto de três níveis de seleção: filogenético (história da espécie), ontogenético (história particular do indivíduo) e cultural (história das práticas culturais).

A temática das relações sociais entre os jovens sob o aspecto das habilidades sociais é bastante explorada na literatura internacional e nacional, mas são raros os exemplos de estudos que apresentam esse assunto no enfoque educacional, mais especificamente no ensino médio. Inúmeros estudos fazem relações entre habilidades sociais e psicopatologias no contexto clínico, evidenciando uma tendência nas pesquisas sobre habilidades sociais. O estudo de Murta (2005) faz uma análise da produção brasileira a respeito das aplicações do treinamento em habilidades sociais e aponta uma concentração de estudos na área clínica. A autora realizou uma consulta a periódicos, base de dados Lilacs e livros produzidos por grupos de pesquisa e identificou 17 programas de intervenção, dos quais dez se voltam para o contexto clínico.

Outro dado relevante a respeito dos estudos sobre habilidades sociais no Brasil é encontrado no estudo de Bolsoni-Silva et al. (2006). Os autores realizaram uma busca nas bases de dados digitais Lilacs, IndexPsi, Psicoinfo e SciELO entre novembro de 2002 e janeiro de 2003, e coletaram informações também junto a editores de periódicos, bibliotecas e autores/pesquisadores, entre dezembro de 2003 e março de 2004. Como retorno dessa coleta de dados, os autores obtiveram a identificação de 65 trabalhos que foram avaliados como pertinentes à área de treinamento em habilidades sociais. O levantamento realizado aponta que desses 65 trabalhos somente dez trabalham com amostras não clínicas de adolescentes.

De acordo com Feitosa, Matos, Del Prette e Del Prette (2009), no contexto da psicologia escolar e da educação, há muitas pesquisas indicando importantes relações entre relacionamentos sociais e vida acadêmica. Nesse trabalho, entre outros resultados, verificou-se que os adolescentes sem dificuldades de aprendizagem tenderam a relatar mais habilidades sociais assertivas do que seus colegas com baixo desempenho acadêmico e com dificuldades de aprendizagem.

O aprofundamento no campo das relações sociais, mais especificamente sob a ótica das habilidades sociais, é também importante para a compreensão da vida escolar do jovem no ensino médio, fornecendo não somente evidências sobre como este se relaciona com seus pares e professores, mas também podendo levantar informações que auxiliam na compreensão da aprendizagem e do desenvolvimento acadêmico do aluno. Tendo em vista a ausência de estudos brasileiros que envolvam essa compreensão a respeito do ensino médio, o presente estudo teve por objetivo compreender 
como se dão as relações sociais entre os alunos do ensino médio, sob a perspectiva das habilidades sociais, verificando se existem diferenças nas habilidades sociais quanto a gênero, idade e série entre os alunos que cursam o ensino médio.

\section{Método}

\section{Participantes}

Participaram do presente estudo 175 alunos de ensino médio de escolas públicas dos municípios de Campinas/SP (escola A) e Pedreira/SP (escola B). A escola A concentrou a maioria dos participantes da pesquisa, com o correspondente a $67,12 \%$ da amostra, enquanto a $B$ deteve $32,88 \%$ do grupo amostral.

Tanto a escola A quanto a B localizam-se na periferia de suas respectivas cidades. A escola A funciona nos períodos diurno e noturno. No período diurno, tem classes do $6^{\circ}$ ao $9^{\circ}$ ano do ensino fundamental e da $1^{\mathrm{a}}$ à $3^{\mathrm{a}}$ série do ensino médio. Já no período noturno, oferece somente ensino médio, da $1^{a}$ à $3^{a}$ série. A escola $B$ oferece somente $1^{\mathrm{a}}, 2^{\mathrm{a}}$ e $3^{\mathrm{a}}$ séries do ensino médio nos períodos diurno e noturno.

Os participantes do estudo tinham idade variando entre 14 e 19 anos. Os jovens com idade entre 15 e 18 anos representam 94,52\% da amostra, o que está em consonância com a regulamentação do Ministério da Educação (Brasil, 2012). Quanto ao gênero dos participantes, observou-se na amostra uma maior participação de sujeitos do sexo feminino - 132 pessoas -, contra 83 indivíduos do sexo masculino.

Os jovens participantes deste estudo dividem-se em: $36,99 \%$ na $1^{\text {a }}$ série, $27,40 \%$ na $2^{a}$ série e $35,62 \%$ na $3^{a}$ série. A respeito da divisão dos alunos por turno, a distribuição é pouco uniforme, já que há o triplo de alunos no período diurno (168 alunos), em relação ao período noturno (51 alunos). Outro dado importante que caracteriza a amostra do presente estudo é a ampla tendência verificada nos participantes de intenção de ingresso no ensino superior. A maioria do grupo amostral respondeu que pretende ingressar no ensino superior, com um percentual de 94,79\%.

Um último dado relevante para a caracterização da amostra envolve a questão do trabalho remunerado para o jovem do ensino médio. Observou-se que $36,32 \%$ dos participantes declararam exercer alguma atividade remunerada, enquanto $63,68 \%$ responderam que não exercem trabalho remunerado.

\section{Materiais}

Os dados foram coletados por meio de dois instrumentos: um questionário de caracterização dos participantes e a escala Matson de avaliação de habilidades sociais para jovens (Matson evaluation of social skills with youngsters - Messy) (Matson, Rotatori, \& Helsen, 1983). O questionário de caracterização teve como foco a coleta de informações a respeito do aluno participante da pesquisa, contemplando as variáveis: idade, gênero, período e série em que estuda, nome da escola, tipo de estabelecimento em que cursou o ensino fundamental (público ou privado), o tipo do curso do 
ensino fundamental (convencional ou supletivo), intenção de concluir o ensino médio, intenção de ingressar no ensino superior, retenção em alguma série, se exerce trabalho remunerado e como este se caracteriza (período e jornada) e nível de estudo dos pais.

Já a escala Messy apresenta como objetivo avaliar as habilidades sociais dos jovens a partir de itens que versam sobre circunstâncias de relacionamentos interpessoais em diversas situações sociais típicas da juventude/adolescência. Trata-se de uma escala com 62 itens do tipo Likert de 5 pontos que contemplam afirmativas que variam de "não corresponde" a "corresponde totalmente". Essa escala foi publicada originalmente em um estudo de Matson et al. (1983), a partir de estudos que utilizaram grupos amostrais dos Estados Unidos. Os itens dessa escala originalmente foram relacionados em seis fatores: habilidades sociais adequadas, assertividade inadequada, impulsividade/teimosia, excesso de confiança, ciúme/"bater em retirada" e itens diversos (que não se encaixavam em nenhuma dessas categorias).

Teodoro, Kappler, Rodrigues, Freitas e Haase (2005) publicaram o primeiro estudo com uma adaptação da Messy para crianças e adolescentes brasileiros. No estudo de Teodoro et al. (2005), a partir de análise fatorial exploratória, os resultados sugeriram uma solução satisfatória para a distribuição dos itens da escala em quatro fatores, denominados: agressividade/comportamento antissocial, habilidades sociais/assertividade, vaidade/arrogância e solidão/ansiedade social. O estudo de Teodoro et al. (2005) demostrou um coeficiente de consistência interna (alfa de Cronbach) de 0,85 . Os quatro fatores da escala - agressividade/comportamento antissocial, habilidades sociais/ assertividade, vaidade/arrogância e solidão/ansiedade social - apresentaram alfa de Cronbach de $0,87,0,84,0,74$ e 0,47 , respectivamente.

\section{Procedimentos para a coleta e análise de dados}

Os dados foram coletados pelos autores e por pesquisadores treinados. Foram utilizados instrumentos impressos, e a coleta ocorreu de forma coletiva. Optou-se neste estudo pelo uso de amostras de conveniência.

Primeiramente foi feito contato telefônico com as duas escolas, agendando uma reunião, quando a pesquisa foi apresentada aos diretores e coordenadores. Nas duas escolas, houve $o$ aceite imediato dos gestores e o agendamento de datas para a coleta de dados.

Nessa visita prévia às escolas, foram explicados os objetivos do estudo, e os pesquisadores apresentaram brevemente o instrumento que seria utilizado a todos os alunos do ensino médio. Além disso, também se explicou sobre a necessidade da assinatura do Termo de Consentimento Livre e Esclarecido (TCLE) pelos pais dos alunos que fossem menores de 18 anos, para que estes pudessem participar da pesquisa, tendo suas respostas sendo analisadas em conjunto com as dos demais participantes do estudo.

Nas datas combinadas para a coleta de dados, o procedimento ocorreu da seguinte forma: o aplicador entrou na sala de aula e identificou-se para o professor (que estava previamente avisado sobre a coleta de dados). Por meio de uma conversa introdutória 
com os alunos, relembrou o que já havia sido explicado na semana anterior, recolheu os TCLEs e iniciou a coleta de dados.

Os dados foram digitados em um banco de dados do software Statistical Analysis System (SAS), versão 8.02. Fez-se a conferência dos dados digitados e desconsideraram-se os instrumentos que não estavam totalmente respondidos. Com o objetivo de identificar as percepções sobre as habilidades sociais dos estudantes, adotou-se a análise descritiva, em que se utilizaram as médias e os desvios padrão. Para verificar se as diferenças entre as médias foram significativas, utilizou-se o teste de Mann-Whitney, quando a análise era relativa a dois subgrupos (por exemplo, gênero) ou o teste de Kruskall-Wallis, quando a análise era relativa a três ou mais subgrupos (por exemplo, séries de estudo). Tais testes foram selecionados devido à não normalidade dos dados constatada pelo teste de Kolmogorov-Smirnof.

\section{Resultados}

A análise descritiva verificou médias de: 4,0 (DP 0,56) para o fator habilidades sociais/assertividade; 1,72 (DP 0,51) para o fator comportamento antissocial/agressividade; 1,75 (DP 0,63) para o fator vaidade/arrogância; e, por fim, 2,29 (DP 0,61) para o fator solidão/ansiedade social. Por meio da análise comparativa, foram verificadas diferenças significativas entre as percepções médias dos estudantes para habilidades sociais/ assertividade (fator 1). Essas percepções se diferenciaram quanto à idade e ao gênero dos estudantes. As percepções relativas ao comportamento antissocial/agressividade (fator 2) diferenciaram-se significativamente quanto à série dos estudantes e ao turno em que estes frequentavam as aulas. Não houve diferença significativa quanto se consideraram as percepções medianas relativas a vaidade/arrogância (fator 3 ) e solidão/ ansiedade social (fator 4 ).

As tabelas 1 e 2 apresentam as comparações dos escores dos quatro fatores da escala Messy entre as variáveis categóricas dos alunos: idade, gênero, período e série. Na Tabela 1, verifica-se diferença significativa nos escores na faixa etária 16-17 no fator habilidades sociais/assertividade, de modo que a média para tal faixa é de 4,16. Para as faixas etárias 14-15 e 18-19, as médias para esse mesmo fator são bastante próximas: 3,84 e 3,86 , respectivamente.

\section{Tabela I. Análise comparativa dos escores dos fatores entre as faixas etárias}

\begin{tabular}{|c|c|c|c|c|c|c|c|c|}
\hline Idade & Variável & $n$ & Média & $\mathrm{DP}$ & Mín. & Mediana & Máx. & Valor $-p^{* *}$ \\
\hline \multirow[t]{4}{*}{$14-15$} & FATOR I & 61 & 3,84 & 0,66 & 1,20 & 3,95 & 4,85 & 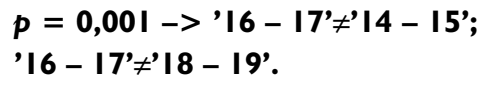 \\
\hline & FATOR 2 & 61 & 1,65 & 0,53 & 1,00 & 1,56 & 3,75 & $p=0,085$ \\
\hline & FATOR 3 & 61 & $\mathrm{I}, 73$ & 0,63 & 1,00 & 1,56 & 3,67 & $p=0,932$ \\
\hline & FATOR 4 & 61 & 2,23 & 0,56 & 1,29 & 2,14 & 3,86 & $p=0,381$ \\
\hline
\end{tabular}


Tabela I. Análise comparativa dos escores dos fatores entre as faixas etárias (conclusão)

\begin{tabular}{lllllllll}
\hline Idade & Variável & $n$ & Média & DP & Mín. & Mediana & Máx. & Valor $-p^{* *}$ \\
\hline I6-I7 & FATOR I & 85 & 4,16 & 0,44 & 3,00 & 4,20 & 4,85 \\
& FATOR 2 & 85 & 1,81 & 0,53 & 1,00 & 1,69 & 3,38 \\
& FATOR 3 & 85 & 1,75 & 0,62 & 1,00 & 1,67 & 3,78 \\
& FATOR 4 & 85 & 2,28 & 0,62 & 1,00 & 2,14 & 3,86 \\
\hline I8-19 & FATOR I & 29 & 3,86 & 0,57 & 2,20 & 4,00 & 4,65 \\
& FATOR 2 & 29 & 1,63 & 0,37 & 1,19 & 1,63 & 2,31 \\
& FATOR 3 & 29 & 1,80 & 0,70 & 1,00 & I,44 & 3,67 \\
& FATOR 4 & 29 & 2,42 & 0,65 & 1,14 & 2,29 & 3,71
\end{tabular}

Fator I: habilidades sociais/assertividade; fator 2: agressividade/comportamento antissocial; fator 3: vaidade/arrogância; fator 4: solidão/ansiedade social.

Fonte: Elaborada pelos autores.

Comparando os escores entre as séries, a Tabela 2 aponta diferenças significativas para o fator agressividade/comportamento antissocial na $2^{\text {a }}$ série do ensino médio, com média de 1,83. Embora a análise estatística aponte que há diferença significativa entre as séries quanto a esse fator especificamente, pode-se afirmar que os escores médios nas três séries é relativamente baixo, considerando que a escala tem 5 pontos (de 1 a 5); as médias para o fator agressividade/comportamento antissocial são de 1,60 na $1^{\text {a }}$ série e 1,76 na $3^{\text {a }}$ série.

Tabela 2. Análise comparativa dos escores dos fatores entre as séries

\begin{tabular}{|c|c|c|c|c|c|c|c|c|}
\hline Série & Variável & $n$ & Média & $\mathrm{DP}$ & Mín. & Mediana & Máx. & Valor $-p^{* *}$ \\
\hline \multirow[t]{4}{*}{$I^{\mathrm{a}}$} & FATOR I & 62 & 3,87 & 0,66 & 1,20 & 4,03 & 4,85 & $p=0,055$ \\
\hline & FATOR 2 & 62 & 1,60 & 0,53 & 1,00 & 1,47 & 3,75 & $p=0,008->$ ' $I^{\prime} \neq 2^{\prime}$ \\
\hline & FATOR 3 & 62 & 1,67 & 0,60 & 1,00 & $\mathrm{I}, 44$ & 3,67 & $p=0,380$ \\
\hline & FATOR 4 & 62 & 2,21 & 0,56 & 1,29 & 2,14 & 3,86 & $p=0,118$ \\
\hline \multirow[t]{4}{*}{$2^{\mathrm{a}}$} & FATOR I & 49 & 3,99 & 0,52 & 2,20 & 4,05 & 4,80 & \\
\hline & FATOR 2 & 49 & $\mathrm{I}, 83$ & 0,44 & 1,00 & $\mathrm{I}, 75$ & 3,00 & \\
\hline & FATOR 3 & 49 & 1,83 & 0,65 & 1,00 & 1,67 & 3,78 & \\
\hline & FATOR 4 & 49 & 2,45 & 0,67 & $\mathrm{I}, 14$ & 2,29 & 3,86 & \\
\hline \multirow[t]{4}{*}{$3^{a}$} & FATOR I & 64 & 4,14 & 0,46 & 2,60 & 4,20 & 4,85 & \\
\hline & FATOR 2 & 64 & 1,76 & 0,53 & 1,00 & 1,63 & 3,38 & \\
\hline & FATOR 3 & 64 & $\mathrm{I}, 77$ & 0,64 & 1,00 & 1,56 & 3,67 & \\
\hline & FATOR4 & 64 & 2,24 & 0,59 & 1,00 & 2,14 & 3,57 & \\
\hline
\end{tabular}

Fator I: habilidades sociais/assertividade; fator 2: agressividade/comportamento antissocial; fator 3: vaidade/arrogância; fator 4: solidão/ansiedade social.

Fonte: Elaborada pelos autores. 
A análise comparativa entre os períodos, como se observa na Tabela 3, mostra diferença significativa no fator agressividade/comportamento antissocial, de modo que os jovens do período noturno apresentam escore médio maior, quando comparados aos jovens do período diurno. Os valores para os jovens do período noturno e diurno são, respectivamente, 1,84 e 1,68, e também podem ser considerados baixos numa escala de 5 pontos.

\section{Tabela 3. Análise comparativa dos escores dos fatores entre os períodos}

\begin{tabular}{|c|c|c|c|c|c|c|c|c|}
\hline Período & Variável & $n$ & Média & DP & Mín. & Mediana & Máx. & Valor $-p^{*}$ \\
\hline \multirow[t]{4}{*}{ DIURNO } & FATOR I & 130 & 3,99 & 0,56 & $\mathrm{I}, 20$ & 4,10 & 4,85 & $p=0,451$ \\
\hline & FATOR 2 & 130 & 1,68 & 0,51 & $\mathrm{I}, 00$ & 1,56 & 3,75 & $p=0,046$ \\
\hline & FATOR 3 & 130 & $\mathrm{I}, 73$ & 0,62 & $\mathrm{I}, 00$ & 1,56 & 3,67 & $p=0,386$ \\
\hline & FATOR 4 & 130 & 2,27 & 0,59 & 1,14 & 2,14 & 3,86 & $p=0,359$ \\
\hline \multirow[t]{4}{*}{ NOTURNO } & FATOR I & 45 & 4,05 & 0,57 & 2,20 & 4,10 & 4,85 & \\
\hline & FATOR 2 & 45 & $\mathrm{I}, 84$ & 0,51 & $\mathrm{I}, 00$ & $\mathrm{I}, 75$ & 3,00 & \\
\hline & FATOR 3 & 45 & $\mathrm{I}, 83$ & 0,67 & 1,00 & 1,67 & 3,78 & \\
\hline & FATOR 4 & 45 & 2,36 & 0,66 & 1,00 & 2,29 & 3,71 & \\
\hline
\end{tabular}

Fator I: habilidades sociais/assertividade; fator 2: agressividade/comportamento antissocial; fator 3: vaidade/arrogância; fator 4: solidão/ansiedade social.

Fonte: Elaborada pelos autores.

$\mathrm{Na}$ Tabela 4, a análise comparativa dos escores dos fatores entre gêneros mostra diferença no fator habilidades sociais/assertividade, pois o gênero feminino apresenta escore médio significativamente maior, quando comparado ao escore do gênero masculino, de acordo com o teste de Mann-Whitney. As médias dos gêneros são: 4,14 (feminino) e 3,76 (masculino).

Tabela 4. Análise comparativa dos escores dos fatores entre gêneros

\begin{tabular}{|c|c|c|c|c|c|c|c|c|}
\hline Gênero & Variável & $n$ & Média & $\mathrm{DP}$ & Mín. & Mediana & Máx. & Valor $-p^{*}$ \\
\hline \multirow[t]{4}{*}{ FEMININO } & FATOR I & 110 & 4,14 & 0,45 & 2,40 & 4,20 & 4,85 & $p<0,001$ \\
\hline & FATOR 2 & 110 & $\mathrm{I}, 70$ & 0,48 & 1,00 & 1,66 & 3,44 & $p=0,687$ \\
\hline & FATOR 3 & 110 & 1,68 & 0,55 & 1,00 & 1,56 & 3,33 & $p=0,236$ \\
\hline & FATOR 4 & 110 & 2,33 & 0,58 & 1,00 & 2,29 & 3,57 & $p=0,124$ \\
\hline \multirow[t]{4}{*}{ MASCULINO } & FATOR I & 65 & 3,76 & 0,65 & 1,20 & 3,90 & 4,85 & \\
\hline & FATOR 2 & 65 & $\mathrm{I}, 77$ & 0,57 & 1,00 & 1,56 & 3,75 & \\
\hline & FATOR 3 & 65 & $\mathrm{I}, 87$ & 0,74 & 1,00 & 1,67 & 3,78 & \\
\hline & FATOR 4 & 65 & 2,22 & 0,65 & 1,14 & 2,00 & 3,86 & \\
\hline
\end{tabular}

Fator I: habilidades sociais/assertividade; fator 2: agressividade/comportamento antissocial; fator 3: vaidade/arrogância; fator 4: solidão/ansiedade social.

Fonte: Elaborada pelos autores. 


\section{Discussão}

Com relação aos dados obtidos por meio da escala Messy, as médias relativas ao fator agressividade/comportamento antissocial mostram-se baixas tanto para meninos como para meninas, 1,77 e 1,70, respectivamente. Nesse sentido, é importante comentar também que a distribuição das respostas da maioria dos 16 itens que compõem esse fator apresenta uma característica marcante para essa constatação de médias baixas. Em 12 dos 16 itens componentes do fator agressividade/comportamento antissocial, observou-se que, no mínimo, 70\% das respostas concentraram-se nas opções 1 e 2 da escala (salvo no item 42 "Eu chamo as pessoas pelos seus nomes", que, por ser invertido, indicou concentração superior a $70 \%$ nas opções 4 e 5 da escala, visto que, nesse caso, chamar as pessoas pelos seus nomes com alta frequência não é um indicativo de agressividade ou de ser antissocial).

No presente estudo, os escores no fator agressividade/comportamento antissocial não apresentaram diferenças significativas entre os grupos "gênero feminino" e "gênero masculino", de acordo com o teste de Mann-Whitney, embora os valores médios absolutos fossem ligeiramente superiores para o gênero masculino. Tal resultado difere do verificado em outros estudos (Teodoro et al., 2005; Méndez, Hidalgo, \& Inglés, 2002).

De acordo com outros estudos já realizados com a escala Messy, como os de Teodoro et al. (2005) e Méndez et al. (2002), os valores apresentados no fator agressividade/comportamento antissocial sempre se apresentam significativamente superiores no gênero masculino. É importante salientar aqui que a publicação de Teodoro et al. (2005) refere-se a uma amostra brasileira (o primeiro estudo brasileiro com esse instrumento). De acordo com a revisão de literatura, somente os dados apresentados no estudo original que propiciou a construção da Messy (Matson et al., 1983) não apresentaram essa característica. No entanto, é importante ressaltar que essa diferença em relação aos outros estudos realizados com essa escala pode referir-se ao fato de esta amostra ser composta exclusivamente por adolescentes e jovens, enquanto nos outros estudos a amostra também envolvia crianças.

No presente estudo, embora as médias encontradas nesse fator não tenham apresentado diferenças significativas entre gêneros, é importante salientar que essas médias não foram altas, ficando entre 1,77 (meninos) e 1,70 (meninas). Também é importante frisar que as questões das escalas utilizadas nos diferentes estudos são bastante distintas, dado que a Messy praticamente não contempla comportamentos enquadráveis como furto ou vandalismo.

Um estudo de Lopes (2005) que envolveu bullying e agressividade faz um panorama sobre o assunto na literatura internacional. O autor aponta que a agressividade e as práticas antissociais entre alunos de instituições de educação básica são menos frequentes no ensino médio e na educação infantil, entretanto observa-se, no ensino fundamental, um aumento da prevalência dessas práticas entre alunos de 11 a 13 anos de idade. Lopes (2005) também salienta que os meninos compõem a maior parte dos agressores. 
Diversos estudos têm apontado características marcantes das instituições de ensino e do aparato social-familiar no desenvolvimento das habilidades sociais (Bandeira et al., 2006; Teodoro et al., 2005; Bolsoni-Silva, 2002; Del Prette \& Del Prette, 1998; Lopes, 2005). Nesse sentido, por exemplo, Teodoro et al. (2005) apontam significativas diferenças nas habilidades sociais entre alunos de instituições de ensino de bairros de classe média e de instituições de ensino localizadas em favelas, e, neste último grupo, observaram-se valores mais baixos. Teodoro et al. (2005) salientam que diversas condições socioeconômicas, estresse psicológico e questões relacionadas ao relacionamento familiar (como desemprego e violência) podem estar relacionados a esse panorama de desigualdade observado no âmbito das habilidades sociais.

No presente estudo, não há uma comparação entre instituições que representem diferentes faixas socioeconômicas. Não se pretende estabelecer qualquer tipo de correlação entre pobreza e desenvolvimento de habilidades sociais. Mas faz-se necessário observar que os altos escores para o fator habilidades sociais/assertividade e os baixos escores para agressividade/comportamento antissocial indicam boas condições para relações sociais nas duas escolas públicas pesquisadas, o que apresenta boas perspectivas para o desenvolvimento dos alunos, inclusive no âmbito acadêmico, considerando que vários estudos apontam correlação positiva entre habilidades sociais e desempenho acadêmico.

Diante dos dados apresentados, é admissível destacar algumas questões, como uma possível contradição entre escores de agressividade tão baixos e os episódios de violência relacionados ao contexto escolar, costumeiramente divulgados pela mídia. O presente estudo alerta para a cautela necessária em fazer relações entre ambiente escolar e violência, pois, entre os jovens participantes desta pesquisa, verificou-se baixa inclinação à agressividade, o que remete à necessidade de estudos mais profundos acerca das causas da violência escolar e fortalece a concepção de que não se pode atribuir, genericamente, o status de causa da violência nas escolas ao próprio ambiente escolar. Deve-se considerar na discussão do comportamento agressivo, por exemplo, a mesma perspectiva apresentada para o desenvolvimento do comportamento social, que inclui uma ampla análise entre indivíduo, sua história de vida e sua inserção histórico-cultural.

Entretanto, quando se observam baixos escores nos fatores solidão/ansiedade social, pode-se levantar a hipótese de que esses jovens tendem a se relacionar o tempo todo, de modo que a escola se constitui como um importante contexto de socialização, mas provavelmente não é o único espaço onde esses jovens se relacionam. Uma questão a ser desenvolvida em futuros estudos pode consistir em conhecer quais são os espaços e os contextos de socialização entre os jovens, para além da escola.

Também é indicado que se realizem novos estudos com a escala Messy, utilizando amostras maiores e mais representativas da população aqui estudada. Desse modo, será possível obter novos dados que auxiliem na discussão a respeito das habilidades sociais em alunos do ensino médio, possibilitando um aprofundamento nas questões aqui levantadas. 


\section{Referências}

Abramovay, M., \& Castro, M. (2003). Ensino médio: múltiplas vozes. Brasília: MEC, Unesco.

Bandeira, M., Rocha, S. S., Freitas, L. C., Del Prette, Z. A. P., \& Del Prette, A. (2006). Habilidades Sociais e Variáveis Sociodemográficas em Estudantes do Ensino Fundamental. Psicologia em Estudo, 11(3), 541-549.

Bolsoni-Silva, A. T. (2002). Habilidades sociais: breve análise da teoria e da prática à luz da análise do comportamento. Interação em Psicologia, 6(2), 233-242.

Bolsoni-Silva, A. T., Del Prette, Z. A. P., Del Prette, G., Montagner, A. R., Bandeira, M., \& Del Prette, A. (2006). Habilidades sociais no Brasil: uma análise dos estudos publicados em periódicos. In M. Bandeira, Z.A.P. Del Prette \& A. Del Prette (Orgs.). Estudos sobre habilidades sociais e relacionamento interpessoal (pp. 1-45). São Paulo: Casa do Psicólogo.

Brasil (2010). Melhores práticas em escolas de ensino médio no Brasil. MEC - Secretaria de Ensino Básico.

Brasil (2012). Instituto Nacional de Estudos e Pesquisas Educacionais Anísio Teixeira (Inep). Sinopse estatística da educação básica. Recuperado em 20 dezembro, 2012, de http://portal.inep.gov.br/basica-censo-escolar-sinopse-sinopse.

Dayrell, J. (2007). A escola "faz" as juventudes? Reflexões em torno da socialização juvenil. Educação e Sociedade, 28(100), 1105-1128.

Del Prette, Z. A. P., \& Del Prette, A. (1998). Desenvolvimento interpessoal e educação escolar: o enfoque das habilidades sociais. Temas em Psicologia, 6(3), 205-215.

Del Prette, Z. A. P., \& Del Prette, A. (1999). Psicologia das habilidades sociais: terapia e educação. Petrópolis: Vozes.

Feitosa, F. B., Matos, M. G. de, Del Prette, Z. A. P., \& Del Prette, A. (2009). Desempenho acadêmico e interpessoal em adolescentes portugueses. Psicologia em Estudo, 14(2), 259-266.

Gresham, F. M. (2009). Análise do comportamento aplicada às habilidades sociais. In A. Del Prette \& Z. A. P. Del Prette (Orgs.). Psicologia das habilidades sociais: diversidade teórica e suas implicações (pp. 187-229). Petrópolis: Vozes.

Lopes, A. A., Neto (2005). Bullying - comportamento agressivo entre estudantes. Jornal de Pediatria, 81(5), 164-171.

Matson, J. L., Rotatori, A. F., \& Helsel, W. J. (1983). Development of a rating scale to measure social skills in children: the Matson evaluation of social skills with youngsters (Messy). Behavior Research and Therapy, 21(4), 335-340.

Méndez, F. X., Hidalgo, M. D., \& Inglés, C. J. (2002). The Matson evaluation of social skills with youngsters. Psychometric properties of the Spanish translation in the adolescent population. European Journal of Psychological Assessment, 18, 30-42. 
Murta, S. G. (2005). Aplicações do treinamento em habilidades sociais: análise da produção nacional. Psicologia: Reflexão e Crítica, 18(2), 283-291.

Skinner, B. F. (1984). Selection by consequences. The behavioral and brain sciences, 7(4), 477-481.

Teixeira, M. L. T. (2011). Juventude, exclusão e processos educativos. In R. G. Azzi \& M. H. T. A Gianfaldoni. Psicologia e educação (pp. 239-252). São Paulo: Casa do Psicólogo.

Teodoro, M. L. M., Kappler, C. K., Rodrigues, J. L., Freitas, P. M., \& Haase, V. G. (2005). The Matson evaluation of social skills with youngsters (Messy) and its adaptation for Brazilian children and adolescents. Revista Interamericana de Psicología/Interamerican Journal of Psychology, 39(2), 239-246.

Submissão: 17.11.2013

Aceitação: 30.04.2014 